\title{
O Contexto Experimental e a Teoria da Mente
}

\author{
Graciela Inchausti de Jou ${ }^{123}$ \\ Pontifícia Universidade Católica do Rio Grande do Sul \\ Tania Mara Sperb \\ Universidade Federal do Rio Grande do Sul
}

\begin{abstract}
Resumo
Para investigar a aquisição e desenvolvimento da teoria da mente de 58 pré-escolares, entre 3 e 5 anos, de classe alta de Porto Alegre, foram aplicadas 3 tarefas: crença falsa, aparência-realidade e crença, em duas modalidades. Usou-se uma modalidade 2 de cada tarefa para obter melhor desempenho das crianças. Criou-se, também, para a tarefa de crença falsa, uma categoria de justificativa, que permitiu às crianças corrigir as suas respostas iniciais. ANOVA com medidas repetidas mostrou que as crianças de 3 e 4 anos apresentaram um desempenho similar nas 3 tarefas aplicadas, excetuando-se a modalidade 1 de aparência-realidade e de crença falsa, quando consideradas as justificativas das crianças às respostas. Quanto às tarefas utilizadas, estas classificaramse de forma hierárquica em relação à dificuldade: a crença falsa foi a mais difícil, seguida pela aparência-realidade e finalmente a crença. Os resultados são discutidos com relação às exigências cognitivas de cada tarefa e à metodologia.

Palavras-chave: Teoria da mente; crença falsa; contexto.
\end{abstract}

\begin{abstract}
Fifty-eight middle-class 3 to 5 preschool children of Porto Alegre were given 3 tasks in order to examine the acquisition and development of the Theory of mind: false-belief, appearance-reality, and belief, standard and facilitated. The last one was introduced in order to investigate children's best performance on the tasks. Children's justifications to their answers were considered as another modality for the false-belief task, so children could confirm or correct their initial answers. ANOVA with repeated measures showed that 3 and 4-year-olds performed similarly, except for appearance-reality and belief, which was the easiest one. Results are discussed concerning the cognitive demands of each task. Also, children's best performance on the justification modality of the false-belief task is discussed concerning methodological issues and the assessment of children's theory of mind.

Keywords: Theory of mind; false-belief; context.
\end{abstract}

The Experimental Context and the Theory of Mind

Tem-se utilizado o termo teoria da mente para denominar a capacidade da criança de levar em consideração os próprios estados mentais, como também os das outras pessoas, com a finalidade de compreender e predizer o comportamento (Dias, 1992). Esta capacidade daria à criança a possibilidade de considerar o que as outras pessoas pensam e fazem, habilidade necessária em quase todas as situações sociais (Jou \& Sperb, 1999).

Inspirados no estudo de Premack e Woodruff (1978), acerca da presença de uma teoria da mente em chipanzés, Wimmer e Perner (1983) utilizaram esta expressão para significar a atribuição de estados mentais do indivíduo a si próprio e aos outros, com o intuito preditivo do comportamento. Este estudo incorpora as conclusões de Dennett (1978), Pylyshyn (1973) e Bennett (1990), citados em Wellman (1990) e Perner (1991), acerca de que só se poderia atribuir uma teoria da

\footnotetext{
${ }^{1}$ Este estudo foi baseado na dissertação da primeira autora, realizada sob a orientação segunda autora, apresentada no programa de Pós-Graduação em Psicologia do Desenvolvimento da UFRGS.

${ }^{2}$ Endereço para correspondência: Rua Fernando Carneiro 269, 91330100 , Porto Alegre, RS.E-mail:grajou@terra.com.br

${ }^{3}$ As autoras agradecem à Alessandra Mainieri pela ajuda na coleta de dados.
}

mente a um indivíduo se ele demonstrasse entender a crença falsa, ou seja, que a crença conflitava com a realidade. Com base nisso, Wimmer e Perner (1983) desenvolveram uma tarefa chamada de crença falsa, que permitia observar se as crianças pré-escolares eram capazes de interpretar comportamentos através do que elas achavam que outra pessoa pensava a respeito de alguma coisa. A importância prática de poder representar a crença falsa de outra pessoa consiste na utilização desta representação como marco de referência para interpretar ou antecipar a ação da outra pessoa.

A tarefa de crença falsa de Wimmer e Perner (1983) envolve um protagonista chamado Maxi, que guarda um chocolate em determinado lugar, sendo que sua mãe, logo a seguir, troca o chocolate de lugar, enquanto Maxi está fora. Pergunta-se à criança onde o protagonista, quando voltar, irá procurar o chocolate. Se a criança indica o lugar onde o protagonista guardou o chocolate, conclui-se que ela estaria representando, ao mesmo tempo, o que o protagonista está pensando (estado mental) e a realidade (sua própria crença) e, ao representar a representação do protagonista prediziria, então, a ação deste. Se, ao contrário, a criança indica o lugar onde a mãe guardou o chocolate, conclui-se que ela não estaria representando o estado mental do protagonista, 
resolvendo, então, a tarefa, fazendo uso somente da representação da realidade, ou seja, de sua própria crença. Esta criança, portanto, não compreenderia os estados mentais nem como epistêmicos nem como preditivos de uma ação.

Os resultados de Wimmer e Perner (1983) mostraram que nenhuma das crianças de 3 a 4 anos de idade, $75 \%$ das de 4 a 6 anos e $86 \%$ das de 6 a 9 anos indicaram o lugar correto. Foi sugerido, então, que a representação da relação entre os estados epistêmicos de dois ou mais indivíduos surge entre os 4 e 6 anos.

Vários estudos têm mostrado, consistentemente, que a maioria das crianças de 3 anos, ao contrário das de 4, falham nas tarefas de crença falsa (Gopnik \& Astington, 1988; Moses \& Flavell, 1990). Moses e Flavell (1990) consideraram, no entanto, alguns aspectos que poderiam estar levando as crianças pequenas ao insucesso. Entre eles, as dificuldades originadas nas demandas lingüísticas da tarefa. Por exemplo, Siegel e Beattie (1991) incluíram a palavra primeiro na pergunta “Onde o protagonista vai (primeiro) procurar seu brinquedo?". Este procedimento, segundo os autores, facilitaria à criança entender a intenção do experimentador. Lourenço (1992), por sua vez, introduz o verbo pensar na frase "...o gato está na sacada, mas João" pensa que está na garage... Para o autor, assim, a crença falsa ficaria explicada, não tendo a criança que inferí-la. Outros aspectos considerados foram o efeito da interação com um par mais experto (Boyes, 1993) ou do aumento da interação experimentador-criança (Dias, Soares \& Sá, 1994). A introdução destas modificações no contexto experimental levou as crianças menores a um melhor desempenho na tarefa, quando comparado àquele originado do setting tradicional.

Moses e Flavell (1990), no entanto, argumentam que a questão do surgimento da teoria da mente na criança préescolar é difícil de resolver. Aspectos como o que se entende por possuir uma teoria da mente e a possibilidade de acessála tornam esta tarefa difícil. Por exemplo, segundo Lourenço (1992), se for considerado que as crianças têm uma teoria da mente quando atribuem estados mentais a si próprias e aos outros, como desejos, intenções e crenças, há evidências desta capacidade já aos 2 ou 3 anos (Bretherton \& Beeghly, 1982; Leslie, 1987; Wellman, 1990) ou mesmo mais cedo (Fodor, 1992). Crianças destas idades distinguem estados físicos de mentais, por exemplo, que uma banana pode ser comida, mas o pensamento da banana não (Wellman, 1988); são capazes de fazer troça (Dunn, 1991); utilizam truques com parceiros e elaboram mentiras (Chandler, Fritz \& Hala, 1989), todos indicadores de que já existe um conhecimento de que há uma mente que representa o mundo por detrás do comportamento das pessoas. Já Wimmer e Perner (1983), Flavell (1986), Astington e Gopnik (1988), Moses e Flavell (1990) e Perner (1991) consideram que a criança tem uma teoria da mente quando resolve a tarefa de crença falsa. De outro lado, a discrepância entre os resultados dos estudos com relação à compreensão da crença falsa por crianças pequenas, muitas vezes, advém do uso de metodologias diferentes, tais como as de tipo experimental ou naturalísticas.

A linha de separação entre as crianças de 3 e 4 anos, quanto ao desempenho nas tarefas de crença falsa, também existe na tarefa de distinção aparência/realidade (Flavell, 1986). A tarefa consiste em mostrar à criança um objeto de aparência enganosa, por exemplo, uma esponja que parece uma pedra de granito. Aos 3 anos, as crianças parecem não entender esta distinção, mesmo quando treinadas (Flavell, Green \& Flavell, 1986) ou expostas a contextos facilitadores (Flavell, Flavell \& Green, 1983). Estes autores modificaram a tarefa, cobrindo o objeto com um filtro colorido, sendo que, no momento da pergunta, parte do objeto ficava a descoberto. Não era necessário, então, lembrar a cor original, pois a informação de como era o objeto realmente e de como aparecia com o filtro colorido ficava ao alcance da criança.

Uma vez que ambas as tarefas, crença falsa e aparência/ realidade, são resolvidas com sucesso pelas crianças na mesma faixa etária, é lícito supor que estejam examinando a mesma habilidade cognitiva, isto é, aquela que permite à criança lidar com duas representações contraditórias, uma a representação do estado mental e a outra, a representação da realidade.

Com referência à questão do desenvolvimento da teoria da mente, Perner (1991) argumenta que o sucesso da criança na resolução da tarefa de crença falsa dependeria de uma revolução conceitual que ocorreria aos 4 anos de idade. Para Wellman (1990), esta habilidade da criança de 4 anos é precedida pelo sucesso da criança de 3 anos em predizer o comportamento do protagonista em função de sua crença (Bartsch \& Wellman, 1989). Para Wellman (1990), é a partir desta habilidade que evoluirá a de identificar a crença falsa, que seria parte do próprio conceito de crença. Wellman (1990) pondera que, em situações de conflito entre crença e realidade, o baixo desempenho das crianças de 3 anos devese ao fato de que elas priorizam o desejo à crença.

Wellman (1988) também se preocupou em facilitar a tarefa de crença para que as crianças de 3 anos pudessem, mais facilmente, predizer a ação do protagonista, inferindo-a através do acesso perceptual deste, como no exemplo: "Esta é Jane. Hoje de manhã, Jane viu seus marcadores mágicos na mesa, não na estante. Agora ela quer seus marcadores mágicos. Onde irá procurá-los?"

Recentemente, as pesquisas sobre teoria da mente têm procurado esclarecer questões como em que idade se poderia acessá-la no pré-escolar. Ou, que variáveis contextuais, na tarefa de crença falsa, permitiriam um desempenho melhor 
das crianças pequenas. Por último, quais seriam as implicações da interação experimentador-criança no resultado das tarefas.

Tradicionalmente, a metodologia de exame da criança, utilizada nos estudos inspirados pela teoria piagetiana, tenta desvendar a forma como a criança pensa a solução do problema. Isto tem sido feito, permitindo a ela justificar suas respostas. Este procedimento permite à criança refletir sobre a sua primeira resposta e, também, explicar o processo de resolução da tarefa, o que evidenciaria as estratégias empregadas nesta resolução que, sem este procedimento, ficariam ocultas na primeira resposta. Com isto, a criança poderia expressar a sua real capacidade.

Acompanhando a orientação dos pesquisadores em teoria da mente, procurou-se, neste estudo, coletar maiores informações sobre o tempo de surgimento da teoria da mente nos pré-escolares, como algumas tarefas empregadas para examinar o seu desenvolvimento relacionam-se entre si, e qual é a influência do contexto experimental nos resultados apresentados pelas crianças. Tinha-se a expectativa de que as crianças de 4 anos apresentariam um número maior de acertos nas tarefas de crença falsa e aparência e realidade do que as de 3 anos. Com relação à tarefa de crença, esperavase que não houvesse diferenças entre as duas faixas etárias. Também esperava-se que todas as crianças se sairiam melhor na modalidade facilitada das tarefas e, especialmente bem, na tarefa de crença falsa, quando lhes era dada a oportunidade de justificar suas respostas.

\section{Método}

\section{Participantes}

Participaram do estudo 58 crianças (metade meninos e metade meninas) de classe média alta de Porto Alegre, com idades compreendidas entre 3 e 5 anos, agrupadas por nível: no nível 1 (Nível A) foram 20 crianças entre 4 anos e 8 meses e 5 anos; no nível 2 (Maternal II), 20 crianças entre 3 anos e 10 meses e 4 anos e 7 meses; no nível 3 (Maternal I), 18 crianças entre 3 anos e 3 anos e 7 meses.

\section{Instrumentos e Material}

Para responder as questões do estudo, foram escolhidas 3 tarefas, entre as mais usadas pelos investigadores, cada uma delas apresentada em duas modalidades, padrão (1) e facilitada (2). As tarefas envolveram o uso de maquetes e bonecos playmobile. O protagonista da história era do gênero correspondente ao da criança. Maxi (Wimmer \& Perner, 1983) e João (Lourenço, 1992) foram utilizados para testar a crença falsa, nas modalidades 1 e 2 , respectivamente. Para testar a crença, usou-se, para a modalidade 1, Sam e para a 2, Jane (ambas, cf. Bartsch \& Wellman, 1989). Aparência e realidade foi investigada utilizando-se variações de duas tarefas criadas por Flavell e colaboradores (1983, 1986): respectivamente, para a modalidade 1 , um imã com aparência de brigadeiro, e para a 2, uma pedra de granito e uma bola de borracha com aparência de pedra de granito.

\section{Delineamento e Procedimento}

Depois de uma semana de familiarização, as crianças escolhidas foram convidadas, individualmente, a participar de uma brincadeira com historinhas, em uma sala familiar a elas.

Para a testagem da crença falsa, modalidade 1 , apresentavase à criança um cenário com dois bonecos playmobile (os protagonistas), e duas caixinhas de plástico (os dois armários, azul e laranja). Contava-se à criança que Maxi estava esperando pela mãe, que havia ido ao supermercado comprar chocolate para fazer um bolo. Maxi ajudou a mãe a guardar o chocolate no armário azul e, então, foi brincar no pátio. Ao fazer um bolo, a mãe pegou o chocolate e depois de usar um pouco, o colocou no armário laranja. Ao terminar o bolo, a mãe saiu da cozinha e, quando Maxi voltou do pátio com fome, lembrou que havia posto o chocolate no armário azul. Perguntava-se, então, onde Maxi iria procurar o chocolate, primeiro (ou no armário azul ou no laranja). Para a modalidade 2 , o cenário incluía uma casa de boneca com um boneco playmobile, o João, que estava procurando o seu gatinho. Com a intenção de facilitar a compreensão da criança, dizia-se a ela, explicitamente, que João pensa que seu gatinho está no quarto, quando, na realidade, está na sala. Perguntavase, então, onde João iria procurar o gatinho primeiro (na sala ou no quarto da mãe).

Crença, modalidade 1, foi testada criando-se um cenário composto por duas casinhas de brinquedo (casa e garage) e introduzindo um boneco playmobile (protagonista). Contavase à criança que João/Maria estava brincando na garage com seu ursinho, quando sua mãe chama-o/a para lanchar. Sai, então, deixando o ursinho na garage. Após, quer seu ursinho para brincar no pátio. Pergunta-se, então, onde João/Maria procurará o brinquedo (garage/casa). Na modalidade 2, conta-se uma história de um personagem que viu seu patinho no sofá e não na mesa, facilitando a tarefa da criança ao enfatizar o aspecto perceptivo. Pergunta-se onde a criança irá procurar pelo patinho.

Para testar aparência/realidade, na modalidade 1 , mostrase à criança um imã de geladeira que parece um brigadeiro, perguntando-se a ela, depois que examina o objeto, com o que este se parece (imã ou brigadeiro). Na modalidade 2, mostra-se uma pedra de granito e uma bola de borracha parecida com a pedra. Com um objeto em cada mão, perguntase o que são. Depois de responder, convida-se a criança a examinar os objetos e pergunta-se, novamente, o que são. 
Finalmente, pergunta-se qual dos dois objetos é a pedra de verdade e qual é o que parece com uma pedra.

Utilizaram-se 6 sessões de testagem para cada criança. Para contrabalançar a ordem de apresentação das tarefas, as crianças foram separadas em 4 grupos, em cada idade. A testagem das mesmas crianças nas duas modalidades das tarefas levou duas semanas, respeitando-se os intervalos entre as tarefas.

\section{Resultados}

A Análise de Variância com Medidas Repetidas foi utilizada para testar as hipóteses deste estudo. Quando indicado, foi utilizado o teste $t$ para amostras emparelhadas, para comparar pares de médias.

As percentagens médias e desvios-padrão dos acertos, nas duas modalidades de cada tarefa, por grupo, sexo, idade e nível, são apresentados na Tabela 1.

Realizou-se uma primeira análise, com a finalidade de investigar se a ordem de administração das tarefas (grupo) influenciou nas respostas das crianças. A análise não revelou um efeito principal significativo para grupo $[F(3,53)=0,18$, $p<0,908]$, indicando que os resultados das crianças não se alteraram significativamente em função da ordem de apresentação das tarefas, em suas duas modalidades.
Também não foi encontrado um efeito principal significativo para gênero nas duas modalidades de cada uma das três tarefas $[F(1,55)=1,26, p<0,266]$ mostrando que não houve diferenças significativas entre o desempenho de meninos e meninas.

Como ilustração, a Figura 1 mostra como se distribuíram os acertos de meninos e meninas nas três tarefas:

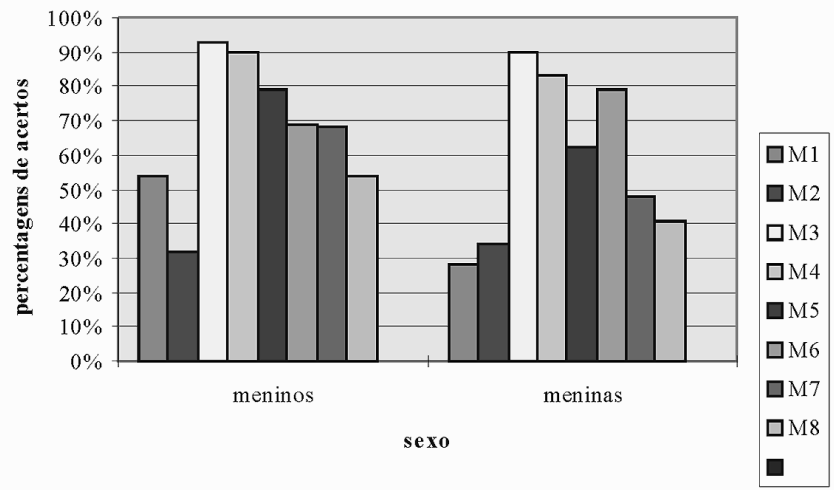

Figura 1. Percentagens de acertos por sexo.

$$
\begin{array}{ll}
\text { M1 }=\text { crença falsa mod.1 } & \text { M2 }=\text { crença falsa mod. } 2 \\
\text { M3 }=\text { crença mod.1 } & \text { M4 }=\text { crença mod. } 2 \\
\text { M5 }=\text { aparência-realid.mod.1 } & \text { M6 }=\text { Aparência-realid. mod.2 } \\
\text { M7 }=\text { justificativa da M1 } & \text { M8 }=\text { justificativa da M2 }
\end{array}
$$

\begin{tabular}{|c|c|c|c|c|c|c|c|c|c|c|c|c|}
\hline \multirow{3}{*}{$\begin{array}{c}N \\
\text { Taref/mod. }{ }^{1}\end{array}$} & \multirow{3}{*}{$\begin{array}{l}\text { Total } \\
(58)\end{array}$} & \multicolumn{4}{|c|}{ Grupo } & \multicolumn{2}{|c|}{ Sexo } & \multicolumn{2}{|c|}{ Idade } & \multicolumn{3}{|c|}{ Nivel } \\
\hline & & (15) & (15) & (14) & (14) & $(29)$ & (29) & (22) & (36) & (20) & (20) & (18) \\
\hline & & 1 & 2 & 3 & 4 & M & F & 3 & 4 & 1 & 2 & 3 \\
\hline \multirow[t]{2}{*}{ M1 } & 0,40 & 0,33 & 0,33 & 0,50 & 0,46 & 0,54 & 0,28 & 0,41 & 0,40 & 0,50 & 0,37 & 0,33 \\
\hline & $(0,49)$ & $(0,49)$ & $(0,49)$ & $(0,52)$ & $(0,52)$ & $(0,51)$ & $(0,45)$ & $(0,45)$ & $(0,50)$ & $(0,51)$ & $(0,50)$ & $(0,49)$ \\
\hline \multirow[t]{2}{*}{ M2 } & 0,33 & 0,47 & 0,20 & 0,36 & 0,31 & 0,32 & 0,34 & 0,23 & 0,40 & 0,45 & 0,32 & 0,22 \\
\hline & $(0,48)$ & $(0,52)$ & $(0,41)$ & $(0,50)$ & $(0,48)$ & $(0,48)$ & $(0,48)$ & $(0,43)$ & $(0,50)$ & $(0,51)$ & $(0,48)$ & $(0,43)$ \\
\hline \multirow[t]{2}{*}{ M3 } & 0,91 & 0,93 & 1,00 & 0,79 & 0,93 & 0,93 & 0,90 & 0,86 & 0,94 & 0,95 & 0,95 & 0,83 \\
\hline & $(0,28)$ & $(0,26)$ & $(0,00)$ & $(0,43)$ & $(0,27)$ & $(0,26)$ & $(0,31)$ & $(0,35)$ & $(0,23)$ & $(0,22)$ & $(0,22)$ & $(0,38)$ \\
\hline \multirow[t]{2}{*}{ M4 } & 0,86 & 0,80 & 0,80 & 1,00 & 0,86 & 0,90 & 0,83 & 0,82 & 0,94 & 0,85 & 0,95 & 0,78 \\
\hline & $(0,35)$ & $(0,41)$ & $(0,41)$ & $(0,00)$ & $(0,36)$ & $(0,31)$ & $(0,38)$ & $(0,39)$ & $(0,23)$ & $(0,37)$ & $(0,22)$ & $(0,43)$ \\
\hline \multirow[t]{2}{*}{ M5 } & 0,71 & 0,60 & 0,87 & 0,64 & 0,86 & 0,69 & 0,79 & 0,68 & 0,81 & 0,90 & 0,70 & 0,61 \\
\hline & $(0,47)$ & $(0,51)$ & $(0,35)$ & $(0,47)$ & $(0,50)$ & $(0,41)$ & $(0,49)$ & $(0,51)$ & $(0,38)$ & $(0,31)$ & $(0,44)$ & $(0,51)$ \\
\hline \multirow[t]{2}{*}{ M6 } & 0,74 & 0,60 & 0,87 & 0,64 & 0,86 & 0,69 & 0,79 & 0,68 & 0,81 & 0,90 & 0,70 & 0,61 \\
\hline & $(0,44)$ & $(0,51)$ & $(0,35)$ & $(0,50)$ & $(0,36)$ & $(0,47)$ & $(0,41)$ & $(0,48)$ & $(0,40)$ & $(0,31)$ & $(0,47)$ & $(0,50)$ \\
\hline \multirow[t]{2}{*}{ M7 } & 0,58 & 0,60 & 0,63 & 0,64 & 0,54 & 0,68 & 0,48 & 0,41 & 0,69 & 0,85 & 0,53 & 0,33 \\
\hline & $(0,50)$ & $(0,51)$ & $(0,52)$ & $(0,50)$ & $(0,52)$ & $(0,48)$ & $(0,51)$ & $(0,50)$ & $(0,47)$ & $(0,37)$ & $(0,51)$ & $(0,49)$ \\
\hline \multirow[t]{2}{*}{ M8 } & 0,47 & 0,60 & 0,33 & 0,57 & 0,46 & 0,54 & 0,41 & 0,23 & 0,63 & 0,75 & 0,42 & 0,22 \\
\hline & $(0,53)$ & $(0,52)$ & $(0,49)$ & $(0,51)$ & $(0,52)$ & $(0,51)$ & $(0,50)$ & $(0,43)$ & $(0,49)$ & $(0,44)$ & $(0,51)$ & $(0,43)$ \\
\hline
\end{tabular}

Tabela 1

Percentagem Média e Desvio-padrão dos Acertos em cada Tarefa, em suas duas Modalidades, por Grupo, Sexo, Idade e Nivel

Nota ${ }^{1}$ M1 $=$ crença falsa mod. $1 \quad$ M2 $=$ crença falsa mod. 2

$\mathrm{M} 4=$ crença $\bmod .2$

M7=justificativa da M1

M5=aparência-realid.mod.1

M8=justificativa da M2
M3= crença mod.12

M6= Aparência-realid. mod.2

Desvio-padrão é apresentado nos parênteses. 
Apesar da diferença não ser significativa, os meninos acertaram consistentemente mais do que as meninas a tarefa de crença falsa, modalidade 1 (respectivamente $54 \%$ e $28 \%$ ), e a tarefa de crença falsa modalidade $1 \mathrm{com}$ justificativa (respectivamente 68\% e 48\%). Este resultado indica a possibilidade de que haja, efetivamente, uma diferença de gêneros, não detectada pela análise devido ao pequeno número de sujeitos. Esta diferença entre os sexos não é tão clara com relação às duas modalidades das outras duas tarefas, de crença e aparência-realidade, e à modalidade $2 \mathrm{da}$ tarefa de crença falsa, com e sem justificativa.

No que concerne à diferença entre o número de acertos das crianças de 3 e 4 anos nas tarefas de crença falsa e aparência-realidade, os resultados indicaram que não houve um efeito principal significativo para o número de acertos entre as crianças de 3 e 4 anos nas duas modalidades das três tarefas $[F(1,55)=3,28, p<0,075]$ nem diferenças significativas relacionadas a efeitos de interação idade-tarefa $[F(2,110)=0,70, p<0,497]$, idade-modalidade $[F(1,55)=0,02$, $p<0,894]$ e idade-tarefa-modalidade $[F(2,110)=1,16 ; p<0,316]$. Portanto, as crianças de 4 anos não apresentaram desempenho superior às de 3 anos, nas duas modalidades das tarefas de crença falsa e aparência-realidade, como também não o fizeram, conforme esperado, nas tarefas de crença.

$\mathrm{Na}$ Figura 2, pode-se observar as percentagens médias de acertos das crianças de 3 e 4 anos, nas duas modalidades de cada tarefa. $O$ exame das médias indica que foi na tarefa de crença falsa, modalidade 1 , que as crianças de 3 e 4 anos foram mais parecidas com relação a acertos (respectivamente, $41 \%$ e $40 \%$ ), seguido pelo desempenho nas duas modalidades da tarefa de crença (respectivamente, $86 \%$ e $94 \%$; $82 \%$ e $94 \%$ ). Os dois grupos mostraram maior disparidade, quanto a acertos, na modalidade 1 da tarefa de aparência-realidade e

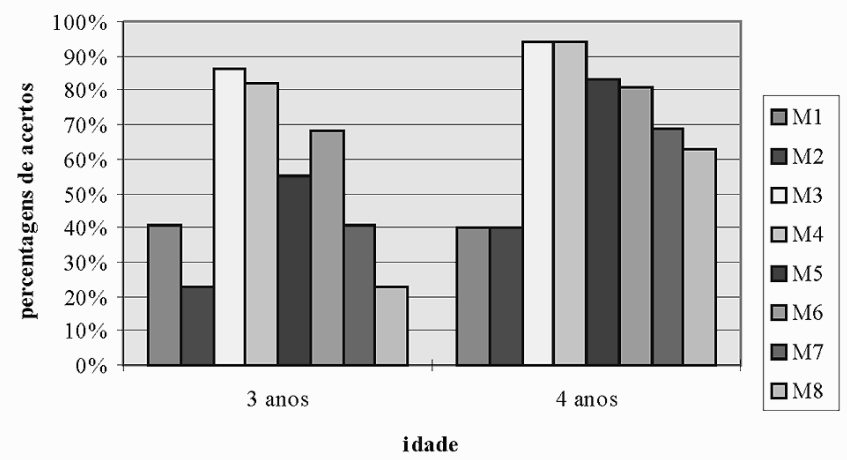

Figura 2. Percentagens de acertos por idade de 3 e 4 anos.

$\mathrm{M} 1=$ crença falsa mod.1

M3 = crença $\bmod .1$

$\mathrm{M} 2=$ crença falsa $\bmod .2$

M5 = aparência-realid. mod.1

M6 = Aparência-realid. $\bmod .2$

M7 = justificativa da M1

M8 = justificativa da M2 nas duas modalidades de crença falsa com justificativa (respectivamente, 55\% e 83\%; 41\% e 69\%; 23\% e 63\%).

Com a finalidade de examinar melhor as diferenças entre as idades, dividiu-se o grupo de crianças por nível escolar, Nível A, Maternal II e Maternal I, respectivamente, nível 1 ( $m=57,60$ meses, $d p=1,31$ meses), nível 2 ( $m=50,55$ meses, $d p=2,72$ meses) e nível 3 ( $m=40,11$ meses, $d p=2,30$ meses). Os resultados indicaram um efeito principal para nível $[F(2,54)=4,81, p<0,01)]$. Análises de Variância para um fator foram levadas a efeito para examinar em que tarefas, nas duas modalidades, ocorreram diferenças entre os níveis. Confirmando a tendência encontrada no exame das percentagens médias de acertos das crianças de 3 e 4 anos, diferenças significativas foram encontradas entre os níveis na modalidade 1 da tarefa de aparência-realidade $[F(2,57)=5,56$, $p<0,006)]$ e nas duas modalidades da tarefa de crença falsa com justificativa (respectivamente, $F(2,56)=6,23, p<0,003$ e $F(2,56)=6,38, p<0,003)$. O teste Tukey indicou que em ambas as tarefas, o nível 3 diferenciou-se significativamente do nível 1 , isto é, as crianças do Maternal I tiveram significativamente menos acertos na modalidade 1 da tarefa de aparência-realidade e nas duas modalidades da tarefa de crença falsa com justificativa, do que as crianças do Nível A. Estes resultados podem ser visualizados na Figura 3.

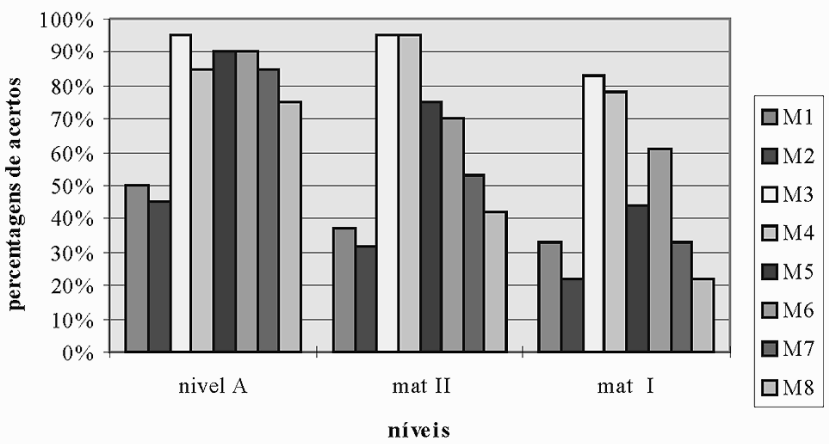

Figura 3. Percentagens de acertos por níveis.

$$
\begin{array}{llrl}
\text { M1 }=\text { crença falsa mod. } 1 & \text { M2 }=\text { crença falsa mod. } 2 \\
\text { M3 }=\text { crença mod. } 1 & \text { M4 }=\text { crença mod. } 2 \\
\text { M5 }=\text { aparência-realid. mod. } 1 & \text { M6 }=\text { Aparência-realid.mod. } 2 \\
\text { M7 }=\text { justificativa da M1 } & \text { M8 }=\text { justificativa da M2 }
\end{array}
$$

Com relação à equivalência de acertos das crianças nas tarefas de crença falsa e aparência-realidade, os resultados mostraram um efeito principal para tarefa: o grupo de crianças de 3 e 4 anos desempenhou de modo diferente as três tarefas $(F(2,110)=49,57, p<0,001)$. Testes $t$ levados a efeito para investigar diferenças entre pares de médias das tarefas indicaram diferença significativa entre a média de acertos nas modalidades 1 das tarefas de crença falsa, aparênciarealidade e crença. 
As crianças tiveram significativamente mais acertos na tarefa de crença do que na tarefa de crença falsa $(t(56)=7,13$; $p<0,001)$. Também tiveram um maior número de acertos na tarefa de aparência-realidade do que na tarefa de crença falsa $(t(56)=4,51 ; p<0,001)$ e mais na tarefa de crença do que em aparência-realidade $(t(57)=3,24 ; p<0,002)$.

Quando se comparam as médias das modalidades 2 aos pares, os testes $t$ também indicam uma diferença significativa entre as modalidades 2 das tarefas de crença falsa, de crença e de aparência-realidade: assim como ocorreu com a modalidade 1, a modalidade 2 da tarefa de crença falsa foi significativamente mais dificil do que a modalidade 2 da tarefa de crença $(t(50)=6,61 ; p<0,001)$ e também significativamente mais dificil do que a tarefa de aparência-realidade $(t(56)=4,87 ; p<0,001)$. $\mathrm{O}$ mesmo não ocorreu com referência à diferença entre as modalidades 2 das tarefas de crença e aparência-realidade: $\mathrm{O}$ número de acertos de ambas se equivaleram, não confirmando, para a modalidade 2, a mesma hierarquia de dificuldade das tarefas da modalidade 1.

Portanto, como já indicado nas análises de efeitos interativos para gênero, idade e modalidade, independente destes fatores, a tarefa de crença foi a mais fácil para todo o grupo de crianças (acompanhada da tarefa de aparênciarealidade, para a modalidade 2). A tarefa de crença falsa, por outro lado, foi a mais difícil para todo o grupo, não se confirmando a equivalência de acertos entre as tarefas de crença falsa e aparência-realidade. A Figura 4 mostra estes resultados.

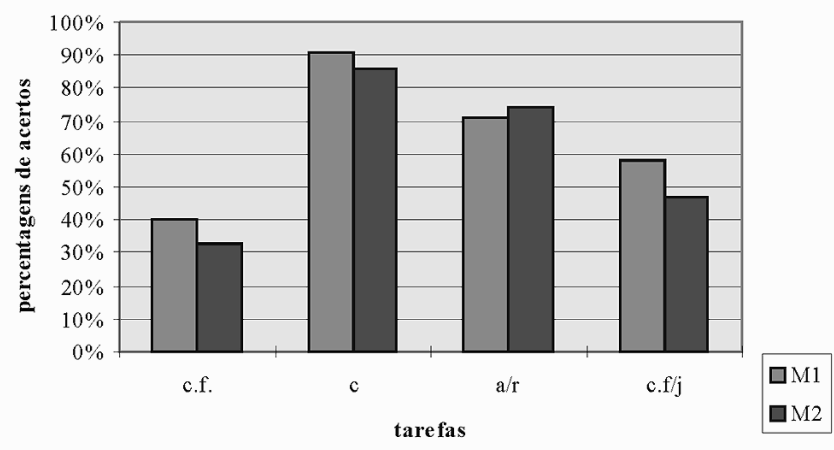

Figura 4. Percentagens de acertos por tarefas e modalidades.

Nota. c.f. $=$ crença falsa c.f $/ \mathrm{j}=$ crença falsa com justificativa c. $=$ crença M1 $=$ modalidade 1 $\mathrm{a} / \mathrm{r}$. = aparência-realid.

$\mathrm{M} 2=$ modalidade 2

Quanto a um melhor desempenho das crianças na modalidade 2 de cada tarefa, os resultados indicaram que houve um efeito principal para modalidade no grupo de crianças. Testes tpost hoc confirmaram os resultados da Análise de Variância.
Com relação ao pedido de justificativa feito às crianças, os resultados mostraram-se de acordo com o esperado, uma vez que as crianças dos dois grupos etários tiveram um número significativamente maior de acertos na tarefa de crença falsa, em resposta ao pedido de justificativa feito após a resposta à modalidade $1[t(56)=-3,45, p<0,001]$ e à modalidade $2[t(56)=-2,66, p<0,01]$. Este resultado indica que, quando convidadas a justificar a primeira resposta dada, as crianças tiveram um número significativamente maior de acertos. Na Figura 5, ilustram-se estes resultados.

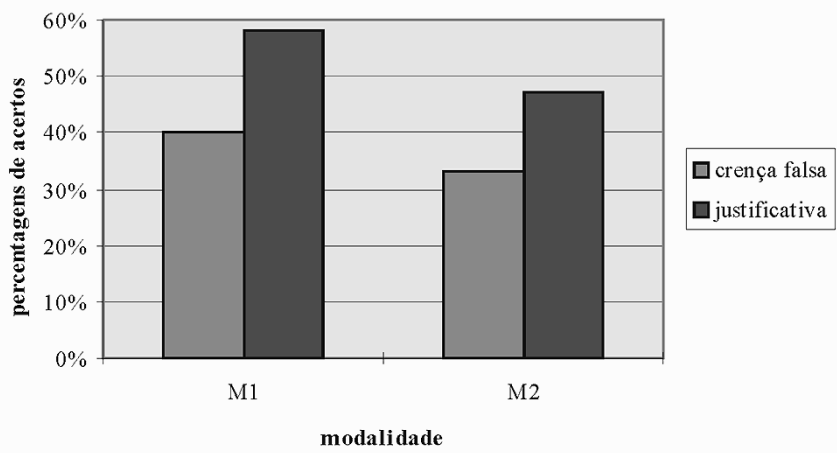

Figura 5. Percentagens de acertos das duas modalidades da tarefa de crença falsa e de crença falsa com justificativa.

Nota. M1=modalidade1; M2=modalidade2

\section{Discussão}

No que concerne aos resultados das crianças de 3 e 4 anos, nas tarefas de crença falsa, aparência-realidade e crença, o que se observou é que, considerando apenas os dois grupos etários, não se manifestaram diferenças. Portanto, a expectativa foi apenas parcialmente confirmada, uma vez que já se esperava que não houvesse diferença na tarefa de crença. Por sua vez, a não-ocorrência de diferença no desempenho entre as crianças de 3 e 4 anos, na tarefa de crença falsa, contraria o conceito de déficit representacional nas crianças de 3 anos, proposto por Perner (1991). Mas, se forem consideradas as justificativas para as respostas de crença falsa e se dividir a amostra, de acordo com os níveis escolares (Maternal I, Maternal II e Nível A), aparecem diferenças entre os grupos extremos, isto é, entre aqueles com média de idade de 4 anos e 10 meses e de 3 anos e 4 meses. O mesmo ocorre com a tarefa de aparência-realidade, na modalidade 1 , ou seja, na modalidade não-considerada como facilitada. Estes resultados alertam para a questão metodológica: de um lado, a questão da amostra, mostrando que a quantidade de sujeitos e a explicitação minuciosa da média de idade dos grupos são aspectos importantes, uma 
vez que as diferenças, neste estudo, não ocorreram entre as idades de 3 e 4 anos, mas sim entre os mais novos de 3 anos e os mais velhos de 4 anos. Por outro lado, com relação à tarefa de crença falsa, é importante salientar a influência, nos resultados, do efeito da situação experimental. Esta influência já se evidenciou no estudo de Dias e colaboradores (1994), quando, com uma amostra de crianças do nordeste brasileiro, foi verificado que, ao manipular-se a linguagem e a interação com o experimentador, os resultados se modificaram para melhor.

Como aporte à discussão teórica, os resultados deste estudo permitem sugerir que há, efetivamente, uma diferença entre as crianças de 3 e 4 anos com relação à tarefa de crença falsa, mas esta diferença não representaria uma linha divisória tão definida no desenvolvimento de uma teoria da mente na criança. Segundo Jou e Sperb (1999), fica ainda sem resposta o que a criança adquire aos 4 anos que propiciaria tal mudança. Seria uma revolução conceitual o que ocorre aos 4 anos, indicando um déficit cognitivo na criança de 3 anos, como propõe Perner (1991), ou um aprimoramento, com o passar do tempo, da capacidade da criança para lidar com os estados mentais e para interpretar as representações dos outros, como propõe Wellman (1990)? Os resultados deste estudo parecem sugerir a segunda possibilidade, opinião que também é compartilhada por Jenkins e Astington (1993, citado em Dalke, 1995), que apontam a variabilidade do desempenho das crianças como um indicador de que esta habilidade de entender crenças falsas desenvolve-se gradualmente.

Dentro desta mesma linha de raciocínio, deve-se considerar ainda que os resultados contrariam aqueles encontrados por Wimmer e Perner (1983), os quais indicaram que nenhuma criança entre 3 e 4 anos, 57\% das crianças entre 4 e 6 anos e $86 \%$ das crianças entre 6 e 9 anos apontaram corretamente, na tarefa de crença falsa, o lugar em que se encontrava o objeto. No presente estudo, que já foi delineado seguindo a facilitação lingüística proposta por Siegel e Beattie (1991), 33\% das crianças pequenas conseguiram acertar a resposta. Portanto, aproximar a situação de testagem da realidade da criança, aqui representada pela facilitação lingǘstica, parece favorecer, como querem Siegel e Beattie (1991) e Glenn, Johnson e Parry (1993), a manifestação das reais capacidades das crianças pequenas, como também das crianças de outras culturas (Dias \& cols., 1994).

A literatura tem fornecido dados que permitem afirmar que as tarefas de crença falsa e de aparência-realidade estão relacionadas (Astington, 1993; Flavell, 1986). Assim, a habilidade que daria condições à criança para afirmar que há diferença entre a crença do protagonista e a realidade, no caso da crença falsa, seria a mesma que permitiria a ela fazer a distinção entre a aparência e a realidade de um objeto ou evento. Este estudo, no entanto, contrariamente ao esperado, não confirmou esta expectativa, já que a hierarquia evidenciada entre as tarefas indicou como mais difícil a tarefa de crença falsa, seguida da de aparência-realidade, sendo a mais fácil, a de crença. Inclusive, a tarefa de aparênciarealidade mostrou-se mais perto da de crença do que da de crença falsa, indicando que, pelo menos para esta amostra de crianças, as tarefas de crença falsa e de aparência-realidade não se equivaleram em dificuldade.

Um último comentário acerca destes resultados diz respeito à aproximação entre os resultados dos testes de crença falsa e aparência-realidade, ambos na modalidade 1 , que foi maior para as crianças de 3 anos, isto é, para as mais novas. Há, portanto, a possibilidade de que a equivalência entre as duas tarefas aconteça para as crianças mais novas, sugerindo que, nessa fase, a criança ainda está desenvolvendo a possibilidade de distinguir duas representações diferentes. Isto mostraria que o distanciamento entre as duas provas ocorreria gradualmente, indicando que, para as crianças mais velhas, é mais fácil distinguir que um objeto pode parecer diferente do que realmente é do que para as mais novas.

Quanto ao exame da influência do contexto experimental no desempenho das crianças nas três tarefas, trabalhos como os de Siegel e Beattie (1991), Lourenço (1992), Glenn e colaboradores (1993) e Dias e colaboradores (1994) mostraram que, dependendo do tipo de contexto experimental empregado, os resultados podem ser diferentes. Neste estudo, a introdução da modalidade 2, como variante contextual facilitadora, não provocou efeitos significativos, no entanto, o contrário aconteceu quando foram consideradas as justificativas dadas para a tarefa de crença falsa.

O aumento dos acertos da criança, depois de ser considerada a justificativa à resposta dada em primeiro lugar, constitui a novidade trazida por este estudo. Examinados os resultados das modalidades 1 e 2 da tarefa de crença falsa - respectivamente $40 \%$ e $33 \%$ - e comparados aos resultados da mesma tarefa, depois da justificativa da resposta - respectivamente $58 \%$ e $47 \%$-, pode-se observar a ocorrência de um aumento significativo no número de acertos das crianças. Estes resultados ficam ainda mais evidentes, quando são comparados por nível: a diferença de desempenho das crianças, após a justificativa, foi maior para as crianças do Nível A ( $m=4$ anos e 10 meses), nas duas modalidades - respectivamente de $50 \%$ para $85 \%$ e de $45 \%$ para 75\%, menor para as crianças do Maternal II ( $m=4$ anos e 3 meses) - respectivamente $42 \%$ para $53 \%$ e $32 \%$ para $42 \%$ - e nula para as crianças do Maternal I ( $m=3$ anos e 4 meses). Com relação às crianças do Maternal I, filmes e anotações de campo mostraram as dificultadas que estas crianças tiveram para memorizar os aspectos mais salientes da história, prestar atenção pelo tempo necessário e, 
principalmente, usar a linguagem verbal para explicar as respostas, o que prejudicou acentuadamente as justificativas às respostas que, em sua maioria, foram dadas através de gestos.

Várias hipóteses podem ser levantadas para explicar a alteração no número de acertos ocorrida após a justificativa às respostas dadas em primeiro lugar, no caso das crianças do Nível A e das do Maternal II. De acordo com a teoria piagetiana, quando, por exemplo, pergunta-se à criança: "porque tu achas que (o protagonista) vai buscar o (objeto) ai??", se estaria provocando o desequilíbrio necessário para uma nova acomodação e assimilação por regulações sucessivas (Piaget, 1976). Isto aconteceria, particularmente, nos casos de mudança da resposta, quando outros observáveis surgiriam. Já quando a resposta não muda, mas, na justificativa, a criança esclarece, por exemplo, que: "...a mãe (ou outro) contou para ele/ela onde estava o chocolate" ou o protagonista "ficou espiando", a criança teria raciocinado, possivelmente, como nos ensina Wellman (1991), priorizando o desejo (de achar o objeto). A criança, ao mencionar outros elementos na história para justificar sua resposta, deixa claro que está considerando a crença do protagonista a partir do acesso perceptual (estado mental), mas essa crença não está sendo utilizada para resolver satisfatoriamente a tarefa.

Dentro de uma perspectiva vygotskiana, se poderia supor que a criança, ao usufruir da relação com o experimentador, conseguiria mostrar um melhor desempenho. Por exemplo, Boyes (1993) argumenta que levar em conta a perspectiva vygotskiana de internalização permitiria aos investigadores repensar a distinção clássica competência-desempenho. Este autor propõe que o critério atual de competência, em termos de uma teoria da mente funcional, poderia ser substituído por critérios que considerassem aspectos das tarefas que pudessem transformar em sucessos os insucessos atuais. O autor acrescenta que o reconhecimento da natureza essencial da intersubjetividade seria um pré-requisito necessário para auxiliar no debate teórico e experimental. Isto, porque os resultados do estudo de Boyes indicaram um melhor desempenho das crianças, quando estas se engajaram numa interação social com um par mais competente do que quando foram testadas na forma tradicional.

O que aproxima os resultados de Boyes (1993) aos deste estudo é exatamente o apoio que o experimentador dá como par mais competente, quando interage mais intensamente com a criança, ao pedir a justificativa da resposta. Assim, a interação social estaria proporcionando à criança, através do emprego do método clínico de Piaget ou através do espaço intersubjetivo criado pela interação criança-experimentador, fazer novas acomodações (Piaget, 1976) ou atuar no nível de desenvolvimento próximo (Vygotsky, 1984).

Este estudo, portanto, coloca em evidência que a compreensão dos estados mentais, vista através do desempenho nas tarefas da teoria da mente, poderia acontecer mais cedo do que o sugerido pelos resultados às provas usadas de forma padrão. Parece fundamental levar em consideração o contexto experimental, se o objetivo do investigador é o de acessar a real capacidade cognitiva das crianças. Em síntese, o que parece faltar nos estudos sobre teoria da mente é a observação das implicações dos aspectos sociocognitivos nas respostas das crianças às tarefas. De resto, considerar estes aspectos poderia facilitar a junção das duas tradições de pesquisa, que têm sido utilizadas para investigar a aquisição e desenvolvimento da teoria da mente das crianças, ou seja, as tradições experimental e naturalística (Astington \& Olson, 1995; Feldman, 1992).

\section{Conclusões}

A discrepância entre os dados obtidos pelos pesquisadores do desenvolvimento social, que afirmam que existe uma teoria da mente já nas crianças de 2 anos (Bretherton \& Beeghly, 1982; Dunn, 1991) e por aqueles do desenvolvimento cognitivo, que afirmam que só se pode falar de uma teoria da mente quando a criança passa nas tarefas de crença falsa (Astington,1993; Perner, 1991), parece dever-se ao uso de metodologias distintas: os primeiros estariam fazendo uso de estudos naturalísticos, ou seja, da observação da criança em seu ambiente natural e os demais, de uma metodologia experimental (Astington \& Olson, 1995).

Para resolver esta discrepância, Astington e Olson (1995) sugerem que os dois métodos estariam observando diferentes níveis do desenvolvimento de uma capacidade comum subjacente à habilidade de interpretar ações do outro em função dos desejos e crenças deste, chamada de teoria da mente. Sendo assim, como salienta Feldman (1995), não haveria contradição entre estas duas posições.

Continuando, Astington e Olson (1995) esclarecem que os pesquisadores do desenvolvimento cognitivo consideram a criança como um pequeno cientista que, para explicar e predizer suas ações e a dos outros, infere os estados mentais causais subjacentes, como desejos e crenças. Por conseguinte, consideram a criança construindo uma teoria da mente, graças ao desenvolvimento de mecanismos cognitivos apropriados e a um ambiente social provedor de instrumentos culturais. Por outro lado, os pesquisadores do desenvolvimento social consideram que entender os estados mentais não tem relação com a construção de uma teoria, mas sim com a internalização 
da psicologia popular da cultura à qual a criança pertence (Jou \& Sperb, 1999).

No entanto, a procura da ciência experimental/ hermenêutica, ou seja, a união da perspectiva causal e interpretativa, proposta por Astington e Olson (1995), não parece satisfazer autores como Bruner (1995) e Feldman (1992), que argumentam que ambas as perspectivas são irredutivelmente diferentes, admitindo, no entanto, que poderiam ser complementares.

Com relação ao estudo presente, após a análise e discussão dos dados, cabe salientar, também, questões metodológicas. Como a maior parte dos estudos sobre teoria da mente, este estudo surgiu de reflexões cognitivistas e de uma tradição metodológica experimentalquantitativa. As restrições que esta escolha metodológica trouxe impediram que se levasse em conta alguns aspectos sociais que ficaram evidentes durante o exame das crianças. Este estudo mostrou que, ao modificar-se o contexto experimental, favorecendo a interação social com o experimentador, isto é, quando se deu às crianças a oportunidade de justificar suas respostas, o desempenho das de quatro anos aumentou significativamente. Este fato permitiria sugerir, então, que modificando-se a situação experimental de forma adequada às crianças de 3 anos, diminuindo, por exemplo, as exigências referentes à atenção, memória ou inferências lógicas, se poderia, também, obter dados que se aproximassem mais daqueles obtidos pelos pesquisadores do desenvolvimento social. Já que neste estudo, evidenciou-se a dificuldade das crianças de 3 anos em manter a atenção durante o tempo exigido, em memorizar aspectos mais salientes da história e em usar a expressão verbal, torna-se evidente que não se pode utilizar, com estas crianças, o mesmo procedimento que se utiliza com as crianças de 4 anos, uma vez que os resultados acerca da teoria da mente poderiam ser decorrentes do não-desenvolvimento de outras funções cognitivas.

Por outro lado, seria pertinente pensar que a discrepância encontrada entre os dados levantados pelas duas linhas de pesquisa, que investigam a teoria da mente, poderia originar-se não só na metodologia utilizada para pesquisá-la, mas também na definição do que seria teoria da mente. Junto com Lourenço (1992), se poderia argumentar que, se teoria da mente é considerada como a compreensão da causalidade dos estados mentais nas ações, esta já é observável nas crianças pequenas (Bretherton \& Beeghly, 1982; Chandler \& cols. 1989; Dunn, 1991). Se, por outro lado, teoria da mente é considerada como a capacidade da criança de representar uma falsa representação de outro, ou seja, de metarrepresentar, esta só seria observável aos 4 anos de idade ou quando a criança conseguisse passar na tarefa de crença falsa (Astington, 1993; Perner, 1991). Poderse-ia ainda aceitar a proposta de Astington e Olson (1995), que consideram que as duas linhas de pesquisa, na verdade, estariam observando diferentes fases do desenvolvimento da teoria da mente.

De um modo geral, o que é importante levar em consideração é que, se há maneiras de transformar os insucessos das crianças em sucessos, ao levar-se em conta os aspectos contextuais, estes aspectos não podem ser ignorados, sob pena dos resultados encontrados não oferecerem confiabilidade (Bruner, 1995). Caberia perguntar, então, como faz Feldman (1992), quais são as novas regras para se estudar a mente humana.

\section{Referências}

Astington, J. W. \& Gopnik, A. (1988). Knowing you've changed your mind: Children's understanding of representational change. Em J. W. Astington, P. L. Harris \& D. R. Olson (Orgs.), Developing theories of mind (pp. 193-206). Cambridge: Cambridge University Press.

Astington, J. W. (1993). The child's discovery of the mind. Cambridge, MA: Harvard University Press.

Astington, J. W. \& Olson, R. (1995). The cognitive revolution in children's understanding of mind. Human Development, 38, 179-189.

Bartsch, K. \& Wellman, H. M. (1989). Young children's attribution of action to beliefs and desires. Child Development, 60, 946-964.

Boyes, M. (1993). Internalization of social discourse: A Vygotskian account of the development of young children's theories of mind. Trabalho apresentado no Biennial Meeting of the Society of Research in Child Development (60th, New Orelans, LA) (pp. 25-28).

Bretherton, I. \& Beeghly Y, M. (1982). Talking about internal states: The acquisition of an explicit theory of mind. Developmental Psychology, 18(6), 906-921.

Bruner, J. (1995). Comentary. Human Development, 38, 204-213.

Chandler, M. J., Fritz, A. S. \& Hala, S. (1989). Small scale deceit: Deception as a marker of 2, 3 and 4 year- olds' early theories of mind. Child Development, 60, 1263-1277.

Dalke, D. E. (1995). Explaining young children's difficulty on the false belief task: Representational deficits or context-sensitive knowledge? British Journal of Developmental Psychology, 13, 209-222.

Dias, M. G. B. B. (1992). Até quando preciso usar a imaginação? Psicologia: Teoria e Pesquisa, 8, 351-361.

Dias, M. G. B. B., Soares, G. B. \& Sá, T. P. (1994). Conhecimento sobre a mente e compreensão sobre as intenções do experimentador. Psicologia: Teoria Pesquisa, 10, 221-229.

Dunn, J. (1991). Young children's understanding of other people: Evidence from observation within the family. Em D. Frye \& C. Moore (Orgs.), Children's theories of mind: Mental states and social understanding (pp. 97-114). Hillsdale, NJ: Erlbaum.

Feldman, C. F. (1992). The New Theory of Mind. Human Development, 35, 107-117.

Flavell, J. H. (1986). The development of children's knowledge about the appearencereality distiction. American Psychologist, 41(4), 418-425.

Flavell, J. H., Flavell, E. R. \& Green, F. L. (1983). Development of the appearancereality distinction. Cognitive Psychology, 15, 95-120. 
Flavell, J. H., Green, F. L. \& Flavell, E. R. (1986). Development of knowledge aabout the appearence-reality distinction. Monograph of the Society for Research in Child Development, 61, 915-928.

Fodor, J. A. (1992). Discussion: A theory of the child's theory of mind. Cognition, 44, 283-296.

Glenn, S. M., Johnson, K. \& Parry, F. (1993). Onset of theory: Methodological considerations. Early Child Development and Care, 86, 39-51.

Gopnik, A. \& Astington, J. W. (1988). Children's understanding of representational distinction. Child Development, 59, 1366-1371.

Jou, G. I. \& Sperb, T. M. (1999). Teoria da mente: Diferentes abordagens. Psicologia: Reflexão e Crítica, 12, 287-306.

Leslie, A. M. (1987). Pretence and representation: The origins of "theory of mind". Psychological Review, 94, 412-416.

Lourenço, O. (1992). Teorias da mente na criança e o desenvolvimento de crenças falsas: falsas de quem? Análise Psicológica, 4, 431-442.

Moses, L. J. \& Flavell, J. H. (1990). Inferring false beliefs from actions and reactions. Child Development, 61, 929-945.

Perner, J. (1991). Understanding the representational mind. Cambridge, MA.: Bradford Books/MIT Press.
Piaget, J. (1976). A equilibração das estruturas cognitivas (Presses Universitaires de France, Trad.). Rio de Janeiro: Zahar. (Original publicado em 1975)

Premack, D. \& Woodruff, G. (1978). 'Does the chimpanzee have a theory of mind?' Behavioural and Brain Science, 1, 515-526.

Siegel, M. \& Beattie, K. (1991). Where to look first for children's knowledge of false beliefs. Cognition, 38, 1-12.

Vygotsky, L. S. (1984). A formação social da mente. São Paulo: Martins Fontes.

Wellman, H. M. (1988). First steps in the child's theorizing about the mind. Em J. W. Astington, P. L. Harris \& D. R. Olson (Org.), Developing theories of mind (pp. 64-92). Cambridge: Cambridge University Press.

Wellman, H. M. (1990). The child's theory of mind. Cambridge, MA: Bradford Books/ MIT Press.

Wimmer, H. \& Perner, J. (1983). Beliefs about beliefs: Representation and constraining function of wrong beliefs in young children's understanding of deception. Cognition, 13, 103-28.

Sobre as autoras

Graciela Inchausti de Jou é Psicóloga, Mestre e Doutora em Psicologia pelo Programa de Pósgraduação em Psicologia do Desenvolvimento da Universidade Federal do Rio Grande do Sul. É Professora da Faculdade de Psicologia da Pontifícia Universidade Católica do Rio Grande do Sul.

Tânia Mara Sperb é Psicóloga, Professora do Programa de Pós-graduação em Psicologia do Desenvolvimento da Universidade Federal do Rio Grande do Sul. 